\title{
Anxiety and depression in patients with osteoarthritis: impact and management challenges
}

This article was published in the following Dove Press journal:

Open Access Rheumatology: Research and Reviews

31 October 2016

Number of times this article has been viewed

\author{
Anirudh Sharma' \\ Prtha Kudesia ${ }^{2}$ \\ Qian Shi \\ Rajiv Gandhi \\ 'Division of Genetics and \\ Development, Krembil Research \\ Institute, ${ }^{2}$ Division of Orthopaedic \\ Surgery, Toronto Western Hospital, \\ Toronto, ON, Canada
}

Correspondence: Rajiv Gandhi Division of Orthopaedic Surgery, Toronto Western Hospital, University of Toronto, Toronto, ON M5T 2S8, Canada Tel +l 4166035642

Email rajiv.gandhi@uhn.ca
Background: Anxiety and depression are common psychological comorbidities that impact the quality of life (QoL) of patients. In this systematic review, we 1) determined the impact of anxiety and depression on outcomes in patients with osteoarthritis (OA) and 2) summarized unique challenges these comorbidities present to current OA management.

Patients and methods: A systematic literature search was performed using the OVID Medline and EMBASE databases until April 2016. Full-text research articles published in English from the year 2000 onward with a sample size of $>100$ were included in this review. Eligible research articles were reviewed and the following data were extracted: study author(s), year of publication, study design, and key findings.

Results: A total of 38 studies were included in the present review. The present study found that both anxiety and/or depression were highly prevalent among patients with OA. Patients with OA diagnosed with these comorbidities experienced more pain, had frequent hospital visits, took more medication, and reported less optimal outcomes. Management strategies in the form of self-care, telephone support, audio/video education programs, and new pharmacotherapies were reported with favorable results.

Conclusion: Anxiety and depression adversely impact the QoL of patients with OA. Physicians/ caregivers are highly recommended to consider these comorbidities in patients with OA. Ultimately, a holistic individualized management approach is necessary to improve patient outcomes.

Keywords: osteoarthritis, anxiety, depression, impact, management

\section{Introduction}

Osteoarthritis (OA) is the most common musculoskeletal disease worldwide. ${ }^{1}$ It is characterized by degeneration of the articular cartilage, osteophyte formation, and asymmetric joint space narrowing. ${ }^{2}$ These changes often lead to significant pain and disability and create a substantial individual, societal, and economic burden. ${ }^{3,4}$ Since the incidence and prevalence of OA increase with age, longer life expectancy will only increase these measures in the future. ${ }^{5}$ Current management largely emphasizes on alleviating symptoms and improving function, but for many these interventions do not provide adequate symptom relief. This variability in symptoms and outcomes among individuals with OA cannot be explained by the disease pathology alone.

Several factors are being investigated to explain differences in patient-reported symptoms and outcomes, of which anxiety and depression have begun to emerge as strong candidates. ${ }^{6,7}$ Anxiety is defined as the presence of "fear or nervousness about what might happen". ${ }^{8}$ When this fear produces behavioral and physiological changes, the Diagnostic and Statistical Manual of Mental Disorders, 5th Edition (DSM-V) 
denotes this as anxiety disorder. ${ }^{9}$ Depression, on the other hand, is defined as the presence of sad, empty, or irritable mood. Both anxiety and depression are accompanied by somatic and cognitive changes that can significantly affect an individual's capacity to function. ${ }^{9}$ Outside of OA, studies have consistently reported that anxiety and depression have significant impacts on cardiovascular diseases, chronic respiratory disorders, and gastrointestinal conditions. ${ }^{10-12}$ Patients suffering from chronic painful disabling conditions frequently report anxiety and depression as comorbidities. ${ }^{13}$ This may predispose patients to experience pain more often, as recent evidence suggests that anxiety and depression can alter pain threshold levels. ${ }^{14}$ Since chronic pain in itself can cause or aggravate anxiety and depression, ${ }^{15}$ a vicious cycle begins, which can significantly impact the course and management of these chronic diseases.

Several studies have evaluated the concordance between OA, anxiety, and depression. Although substantial work has been conducted to elucidate the role of anxiety and depression in patients with OA, this study seeks to provide a comprehensive understanding regarding the impact these comorbidities have on OA symptoms, patient outcomes, and challenges they prensent towards disease management.

\section{Patients and methods}

\section{Eligibility criteria}

Original studies of 1) human subjects that 2) assessed anxiety or depression during any time point of the 3) OA disease course 4) regarding its impact on patient-reported symptoms and outcomes along with 5) different interventions employed to manage these comorbidities were included for this review. We limited eligibility to studies that were only in English language. Review articles, letters to the editor, published abstracts, book series, short surveys, notes, editorials, and case series were excluded. It has been reported that even with statistically significant results, studies with low sample sizes are less likely to reflect a true effect; ${ }^{16,17}$ therefore, reports concerning $<100$ patients were excluded. Additionally, only articles with full-text versions published from the year 2000 onward were eligible for this review to focus on recent updates in OA, anxiety, and depression.

\section{Search strategy and criteria}

A manual electronic search of the OVID Medline (from 1996) and EMBASE (from 1974) databases was performed in duplicate by two authors (AS and PK) to identify studies published until April 2016 that assessed the impact or management of anxiety or depression in patients with OA. The following search string was used: "(osteoarthritis) and (anxiety or depression) and (impact or management)". One thousand and sixty-seven records were identified after excluding non-English results. After performing automated deduplication using the OVID search interface, 866 studies remained.

\section{Study selection}

Citation records were extracted to Excel spreadsheet software (Microsoft Corp, Redmond, WA, USA) and sorted by publication-type metadata. No specialized systematic review software packages were used. Publication types not meeting inclusion criteria were removed (Figure 1). These records were manually screened for eligibility by two authors (AS and $\mathrm{PK}$ ), and any doubt regarding inclusion/exclusion of a particular study was addressed by discussion between the two authors. Unresolved conflicts were managed by discussion with two additional authors (QS and RG). Four hundred and thirty-five records were excluded as 233 were review

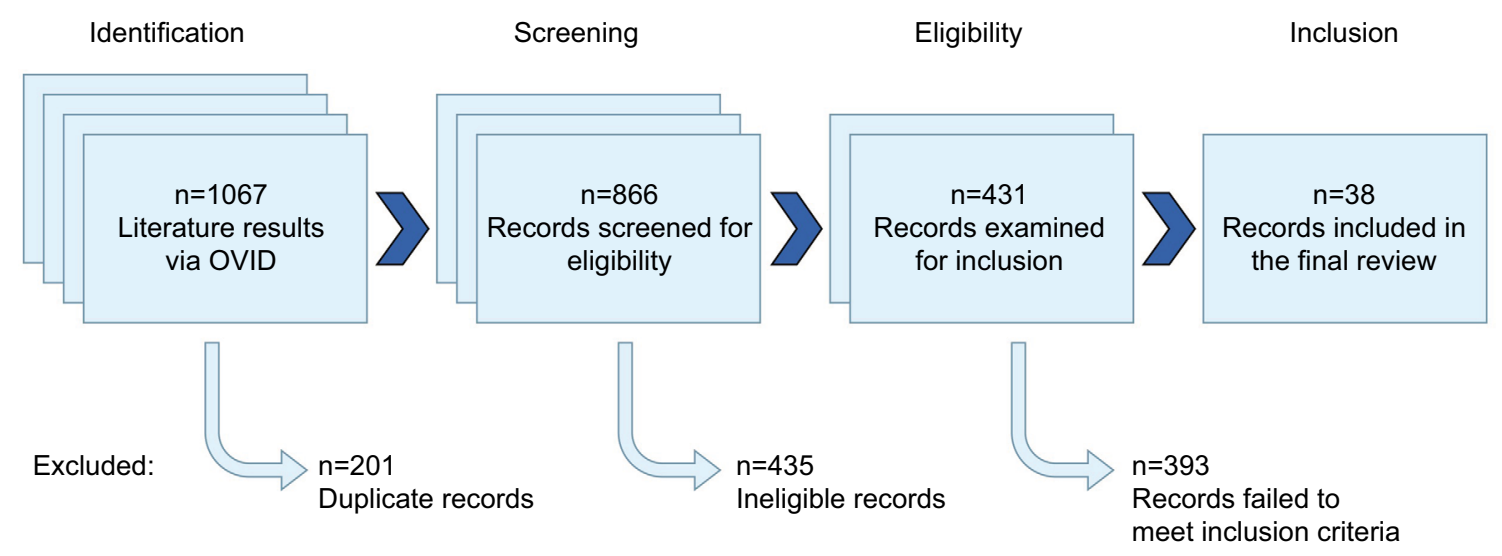

Figure I Flow diagram summarizing the literature search, screening, and review. 
articles, 174 were published abstracts, seven were conference papers, seven were notes, six were editorials, three were short surveys, two were letters, two were meta-analysis, and one was a book series. After excluding further 356 records based on title and abstract information, 21 records with a sample size of $<100$, and 16 records based on year of publication,
38 records were included in the final review. ${ }^{18-55}$ No systematic search of article bibliographies or conference proceedings was performed in an attempt to identify any additional unpublished or otherwise unidentified data. Full-length articles of the remaining 38 records were obtained and included in our final synthesis (Table 1).

Table I Final studies with authors, year of publication, design, and key findings

\begin{tabular}{|c|c|c|c|}
\hline Authors & Year & Design & Key findings \\
\hline Axford et $\mathrm{al}^{55}$ & 2008 & $\begin{array}{l}\mathrm{n}=\mathrm{I} 70 \text { patients completed trial of PEP to determine } \\
\text { what may hinder its efficacy in knee OA. }\end{array}$ & $\begin{array}{l}\text { Greater pain was associated with reduced coping, increased } \\
\text { depression, and reduced physical ability. }\end{array}$ \\
\hline Ayral et $\mathrm{al}^{54}$ & 2002 & $\begin{array}{l}\text { Prospective randomized study of } n=I 12 \text { (56/group) to } \\
\text { access impact of video information on pre-operative } \\
\text { anxiety of patients scheduled to undergo joint lavage } \\
\text { for knee OA. }\end{array}$ & $\begin{array}{l}\text { Pre-operative anxiety was lowered by half for patients who } \\
\text { had viewed the video. Tolerability of knee lavage was also } \\
\text { significantly better in the video group. }\end{array}$ \\
\hline Blagestad et al ${ }^{53}$ & 2016 & $\begin{array}{l}\text { Cross-sectional study of } n=39,688 \text { participants undergoing } \\
\text { THA from } 2005 \text { to } 20 \text { I I to investigate redeemed } \\
\text { medications. }\end{array}$ & $\begin{array}{l}\text { Surgery reduced prescriptions of analgesics, hypnotics, and } \\
\text { anxiolytics, but not anti-depressants. }\end{array}$ \\
\hline Buszewicz et $\mathrm{al}^{52}$ & 2006 & $\begin{array}{l}\text { Randomized controlled trial, } \mathrm{n}=8 \mathrm{I} 2 \text { patients aged } \\
>50 \text { hip and/or knee OA and pain and/or disability } \\
\text { randomized to six sessions of self-management and } \\
\text { education booklet (intervention group) or education } \\
\text { booklet alone (control group). }\end{array}$ & $\begin{array}{l}\text { The two groups showed significant differences at } 12 \text { months } \\
\text { on the anxiety sub-score of HADS. No significant difference } \\
\text { was seen in number of visits to the GP at } 12 \text { months. }\end{array}$ \\
\hline $\begin{array}{l}\text { Collantes-Esteve } \\
\text { and Fernandez- } \\
\text { Perez }^{51}\end{array}$ & 2003 & $\begin{array}{l}\text { Open-label multi-center study with } n=2,228 \\
\text { investigated the effect of a switch from celecoxib to } \\
\text { rofecoxib among patients with OA. }\end{array}$ & $\begin{array}{l}\text { The switch to rofecoxib from celecoxib favorably influenced } \\
\text { proportions of patients with self-reported depression. }\end{array}$ \\
\hline Croft et $\mathrm{al}^{50}$ & 2005 & $\begin{array}{l}\text { Mailed patient survey of } n=8,995 \text { individuals aged } \\
>50 \text { years. Patients completed the SF- } 36, \text { HADS, and } \\
\text { WOMAC. }\end{array}$ & $\begin{array}{l}\text { Severity of knee pain and related disability are worse in the } \\
\text { presence of pain elsewhere. }\end{array}$ \\
\hline Dailiana et $\mathrm{al}^{49}$ & 2015 & $\begin{array}{l}\text { Investigate and compare the impact of primary } \\
\text { THA }(n=I 74) \text { and TKA }(n=204) \text { on QoL, patients' } \\
\text { satisfaction and detect the effect of patients' } \\
\text { demographic and clinical characteristics on outcome. } \\
\text { WOMAC and CES-DI0 pre- and post-operative. }\end{array}$ & $\begin{array}{l}\text { WOMAC and CES-DI0 improved significantly I year post- } \\
\text { operatively. }\end{array}$ \\
\hline Dieppe et $\mathrm{al}^{48}$ & 2000 & $\begin{array}{l}\text { Prospective study, } \mathrm{n}=500 \text { patients, study of natural history } \\
\text { of peripheral joint } \mathrm{OA} \text { and its impact over } 8 \text { years. } \\
\text { Patients reviewed at } 3 \text { and } 8 \text { years. HAQ } \\
\text { and HADS. }\end{array}$ & $\begin{array}{l}\text { The mean HAQ and HADS scores at } 8 \text { years were high, } \\
\text { especially in those with knee disease, indicating significant } \\
\text { disability as a result of the disease. }\end{array}$ \\
\hline Ellis et $\mathrm{al}^{47}$ & 2012 & $\begin{array}{l}\text { Effect of psychopathology on the rate of improvement } \\
\text { following TKA }(n=154) \text {. }\end{array}$ & $\begin{array}{l}\text { Subjects in the psychopathology group showed significantly } \\
\text { lower SF-36 mental component summary scores both at } \\
\text { baseline and I year post-operatively. }\end{array}$ \\
\hline Gerrits et $\mathrm{al}^{46}$ & 2014 & $\begin{array}{l}\text { Prospective analysis of impact of chronic diseases } \\
\text { and pain characteristics in } n=I, I 22 \text { individuals with } \\
\text { remitted depressive or anxiety disorder. }\end{array}$ & $\begin{array}{l}\text { Pain, not chronic disease, increases the likelihood of } \\
\text { depression recurrence, largely through its association with } \\
\text { aggravated sub-threshold depressive symptoms. }\end{array}$ \\
\hline Gignac et $\mathrm{al}^{45}$ & 2013 & $\begin{array}{l}\text { Middle- and older-age adults with } \mathrm{OA}, \mathrm{n}=177 \text { or } \\
\text { no chronic disabling conditions, } \mathrm{n}=193 \text {, aged }>40 \text { years } \\
\text { completed a telephone interview and self-administered } \\
\text { questionnaire assessing demographics, } \mathrm{SRPQ} \text {, and } \\
\text { psychological variables. }\end{array}$ & $\begin{array}{l}\text { Middle-aged adults with OA reported significantly greater } \\
\text { role limitations and more health care utilization than all } \\
\text { other groups. Middle-aged adults and those with OA also } \\
\text { reported greater depression, stress, role conflict, and } \\
\text { behavioral coping efforts than older adults or healthy } \\
\text { controls. }\end{array}$ \\
\hline Hanusch et $\mathrm{al}^{44}$ & 2014 & $\begin{array}{l}\mathrm{n}=100 \text {, influence of psychological factors, including } \\
\text { perception of illness, anxiety, and depression, on recovery } \\
\text { and functional outcome after TKA. Function was assessed } \\
\text { pre-operative, } 6 \text { weeks, and I year after using OKS and } \\
\text { ROM. }\end{array}$ & $\begin{array}{l}\text { Pre-operative function had the biggest impact on post- } \\
\text { operative outcome for ROM and OKS. Depression and } \\
\text { anxiety associated with a higher (worse) knee score at } \\
\text { I year. }\end{array}$ \\
\hline
\end{tabular}


Table I (Continued)

\begin{tabular}{lll}
\hline Authors & Year & Design \\
\hline Hawker et $\mathrm{al}^{43}$ & $201 \mathrm{I}$ & $\begin{array}{l}\text { Community cohort, } \mathrm{n}=529 \text { participants with hip/knee OA. } \\
\text { Telephone interviews assessed OA pain } \\
\end{array}$ \\
& and disability using three time points over 2 years.
\end{tabular}

Kingsbury and

Conaghan $^{42}$

Kirkness et $\mathrm{al}^{4}$

Lin et $\mathrm{al}^{40}$

Lin et $\mathrm{al}^{39}$

Liu et $\mathrm{al}^{38}$

Lopez-Olivo

et $\mathrm{al}^{37}$

$\operatorname{Marks}^{36}$

Marks $^{35}$

Montin et $\mathrm{al}^{34}$

Nour et $\mathrm{al}^{33}$

Ozcakir et $\mathrm{al}^{32}$

2011

Perruccio et $\mathrm{al}^{3 \mid}$

2012 Prospective study of $n=494$ participants who completed patient-reported outcome pre- and 12 months post-TKA

WOMAC, POMS, and HADS scoring methods used.
$\mathrm{n}=\mathrm{I} 24$ patients assessed 24 hours before $(\mathrm{TI})$ and

Pinto et $\mathrm{al}^{30}$

2012

of OA, $n=1,006$ GPs randomly selected and invited

to participate in, on factors influencing their management,

burden on their practice, and on the

need for improving care.

2012 Pre- and post-operative measures of pain, physical function using LEFS, and QoL of $n=168$ patients were evaluated.

2003 Randomized controlled trial, $\mathrm{n}=1,80 \mathrm{I}$, depressed older adults with coexisting arthritis, performed at 18 primary care clinics to evaluate whether care for depression changes pain and outcome.

2006 Multi-site randomized-controlled trial $n=I, 00 I$ participants with depression and arthritis. Baseline and 12-month interviews assessed arthritis pain severity and activity interference, depression, analgesic use, and overall functional impairment.

2016 Patients with primary hand OA, $n=247$, consulting secondary care, underwent physical examination for the number of joints with bony joint enlargements, soft tissue swelling and deformities, and radiographs.

2011 Evaluation of $n=24$ I patients undergoing TKA, before and 6 months after surgery. Multiple regression models evaluated associations of baseline demographic and psychosocial variables.

2007 Cross-sectional analyses, $\mathrm{n}=100$, unilateral and bilateral radiographic and symptomatic knee $O A$ patients underwent standard assessment using several validated questionnaires and a series of walking tests on level ground.

$2009 \mathrm{n}=\mathrm{I}, 000$ hip OA surgical candidates examined for any historical/concurrent evidence of depression/anxiety.

Longitudinal follow-up study, $\mathrm{n}=100$ participants, State Trait Anxiety Inventory was used to measure patients' level of anxiety before surgery and at I month, 3 months, and 6 months post-operatively.

2006 Older adult women $(n=102)$ and men $(n=I I)$ with OA or RA were randomly assigned to experimental $(n=68)$ or wait list control $(n=45)$ groups. CES-D at baseline, pre-intervention, and post-intervention.

$\mathrm{n}=100$ knee OA patients; investigate relationship between radiological severity and clinical/psychological factors. $\mathrm{KL}$, WOMAC, 15 m walk, 10-step climb. 48 hours after (T2) surgery. Demographic, clinical, and psychological factors were assessed at TI and several post-surgical pain issues, anxiety, and analgesic consumption were evaluated at $\mathrm{T} 2$.
Key findings

Current OA pain strongly predicted future fatigue and disability; fatigue and disability in turn predicted future depressed mood; depressed mood and fatigue were interrelated such that depressed mood exacerbated fatigue and vice versa, and that fatigue and disability, but not depressed mood, led to worsening of OA pain.

Achieving adequate pain control and lack of time were the most frequently cited challenges, whereas more time with patients, collaboration with specialist colleagues, and improved communication tools were the most common needs identified to improve OA management.

Most common comorbidities in these patients were osteoarthritis, hypertension, and major depressive disorders.

Benefits of improved depression care extended beyond reduced depressive symptoms and included decreased pain as well as improved functional status and QoL.

Systematic depression management was more effective than usual care in decreasing pain severity among arthritis patients with lower initial pain severity.

Hand OA patients report esthetic dissatisfaction with their hands regularly. This dissatisfaction has a negative impact in a small group of patients who also reported more depression and negative illness perceptions.

Perioperative psychosocial evaluation and intervention are crucial in enhancing TKA outcomes.

Efforts to heighten self-efficacy for pain and other symptoms management may influence the affective status, function, and effort-related perceptions of people with knee OA quite significantly.

Those with depression and anxiety histories were more impaired before surgery and tended to recover more slowly than those with no such history.

Patients' pre-operative trait anxiety impaired HRQoL both before and after surgery.

Self-management intervention can successfully improve involvement in exercise and relaxation among housebound older adults with arthritis.

Depression was significantly higher in late-stage knee OA group. Radiological severity is an important indicative factor for pain, disability, depression, and social isolation.

As symptomatic joint count increase, so does anxiety and depression both pre- and post-operatively. A comprehensive approach to OA management/care is warranted.

Positive correlation between post-surgical anxiety and acute pain was reported. 


\begin{tabular}{|c|c|c|}
\hline Authors & Year & Design \\
\hline $\begin{array}{l}\text { Rosemann } \\
\text { et } \mathrm{al}^{29}\end{array}$ & 2007 & $\begin{array}{l}\text { Survey of } n=I, 02 I \text { participants to assess the } \\
\text { prevalence, severity, and predictors of depression in a } \\
\text { large sample of patients with OA. }\end{array}$ \\
\hline $\begin{array}{l}\text { Rosemann } \\
\text { et } \mathrm{al}^{28}\end{array}$ & 2007 & $\begin{array}{l}\text { Patient questionnaires, } n=I, 02 I \text { to assess the impact } \\
\text { of concomitant depression on } \mathrm{Q} O \mathrm{~L} \text { and health service } \\
\text { utilization of patients with } \mathrm{OA} \text {. }\end{array}$ \\
\hline $\begin{array}{l}\text { Rosemann } \\
\text { et } \mathrm{al}^{27}\end{array}$ & 2007 & $\begin{array}{l}\text { Cross-sectional survey, } \mathrm{n}=\mathrm{I}, 250 \mathrm{OA} \text { patients to assess } \\
\text { factors associated with visits to GPs, orthopedists, and } \\
\text { non-physician practitioners. }\end{array}$ \\
\hline $\begin{array}{l}\text { Rosemann } \\
\text { et } \mathrm{al}^{26}\end{array}$ & 2007 & $\begin{array}{l}\text { Determined factors associated with functional disability in } \\
\mathrm{n}=\mathrm{I}, 02 \mathrm{I} \text { patients with } \mathrm{OA} \text { via questionnaires. }\end{array}$ \\
\hline $\begin{array}{l}\text { Rosemann } \\
\text { et } \mathrm{al}^{25}\end{array}$ & 2008 & $\begin{array}{l}\text { Cross-sectional survey of } n=1,021 \text { OA patients to determine } \\
\text { factors associated with pain intensity in primary care. }\end{array}$ \\
\hline Sale et $\mathrm{al}^{24}$ & 2008 & $\begin{array}{l}\text { Prospective cohort study, } \mathrm{n}=1,227 \text { individuals } \\
\geq 62 \text { years with hip/knee OA completed CES-D, } \\
\text { WOMAC, and other questionnaire. }\end{array}$ \\
\hline
\end{tabular}

Stamm et $\mathrm{al}^{23} \quad 2014$ Health interview survey including $\mathrm{n}=3,097$ subjects aged $>65$ years with OA, back pain, or osteoporosis to explore health care utilization compared to controls.

Steigerwald et $\mathrm{al}^{22}$

Theiler et $\mathrm{al}^{2}$

2012 Open-label, Phase 3b study of $n=195$ patients to evaluate the effectiveness and tolerability of tapentadol for severe, chronic OA knee pain.

2002 3-week prospective open-label multi-center study with rofecoxib $25 \mathrm{mg}$ daily in $\mathrm{n}=134$ (mean 69 years, $\mathrm{SD}=8$ ) outpatients with painful OA flares of the knee or the hip.

Wylde et $\mathrm{al}^{20} \quad 2012$ Patients listed for a primary TKA were recruited from pre-operative assessment clinics. Pre-surgical evaluation included WOMAC, PSES, HAD, and $S A C Q$ questionnaires and questions about other painful joints. Patients then completed the WOMAC Pain and Function Scales at one year post-operatively.

Yilmaz et al ${ }^{19} \quad 2015$ Patients with RA $(n=142)$, FMS $(n=136)$, knee OA $(n=139)$ and healthy women controls $(n=152)$ were analyzed using VAS, BDI, FIQ, TPC, DAS-28, HAQ, and WOMAC.

Zullig et al $^{18}$
2015 Data were from patients $(n=300)$ enrolled in a randomized control trial examined the association of comorbidities with baseline-OA PROs: pain, physical function, depressive symptoms, fatigue, and insomnia.

\section{Key findings}

There is high prevalence of depression among patients with $O A$ and perceived pain and few social contacts were strongest predictors.

Appropriate treatment of depression would appear not only to increase QoL but also to lower costs by decreasing health service utilization.

Psychological factors contribute to the increased use of health care providers.

Main factors associated with functional disability were depression, pain, and few social contacts.

Severity of depression showed the strongest association with pain intensity.

Prevalence of depressive symptoms was high in adults with OA. Higher depressed mood was independently and significantly associated with female gender, greater pain and fatigue, stressful life events, more coping behaviors, and receiving treatment for depression/mental illness.

Patients with OA, back pain, or osteoporosis visited GPs and were hospitalized more often than controls. Problems in the ADLs, pain intensity, and anxiety/depression influenced GP consultations.

Tapentadol significantly improved pain intensity, HRQoL, and function in patients with inadequately managed, severe, chronic OA knee pain.

Rofecoxib significantly SF-I 2 and WOMAC scores, in OA patients.

Significant predictors of post-operative pain were greater anxiety and higher pain severity. Other significant predictors of post-operative disability were greater anxiety, worse functional disability, and a greater number of painful joints elsewhere.

Positive correlation was determined between BDI, VAS, and WOMAC scores in the knee OA group. However, level of depression was only related to disease severity in women with FMS.

Depression was associated with worse pain, fatigue, and insomnia. Evidence that comorbidity burden is associated with worse OA-related PROs.

\begin{abstract}
Abbreviations: AIMS, Arthritis Impact Measurement Scale; ASMP, Arthritis Self-Management Program; BDI, Beck Depression Inventory; CES-D, Centre for Epidemiological Studies Depression Scale; DAS-28, Disease Activity Score-28; FIQ, Fibromyalgia Impact Questionnaire; FMS, fibromyalgia syndrome; GPs, general practitioners; HADS, Hospital Anxiety and Depression Scale; HAQ, Health assessment questionnaire; HSCL-20, Hopkins Symptom Checklist Depression Scale; IPQ-R, Illness Perceptions QuestionnaireRevised; KL, Kellgren-Lawrence grading; KSS, Knee Society Scale; LEFS, Lower Extremity Function; OA, osteoarthritis; OKS, Oxford Knee Score; PEP, Patient Education Program; PHQ-9, Patient Health Questionnaire; POMS, Profile of Mood States; PSES, Pain Self-Efficacy Scale; RA, rheumatoid arthritis; ROM, Goniometer-measured range of movement; SACQ, Self-Administered Co-morbidity Questionnaire; SF-36, SF-I2, Short Form Health Survey; SRPQ, Social Role Participation Questionnaire; THA, total hip arthroplasty; TKA, total knee arthroplasty; TPC, tender point counts; WOMAC, Western Ontario \& McMaster Universities Osteoarthritis Index; VAS, Visual Analog Scale; PROs, Patient-reported Outcomes; ADLs, Activities of Daily Living.
\end{abstract}

\section{Data collection}

Data extraction included the following elements: 1) authors, year of publication, 2) study design, and 3) key findings.

\section{Study designs and study quality}

Of all the final studies included in this review, six were randomized controlled trials, ${ }^{18,33,39,40,52,54} 14$ were prospective cohort studies, ${ }^{20,21,30,31,34,37,41,44,46,48,49,51,55,56} 14$ were cross-sectional studies, ${ }^{19,25-29,32,36,38,43,45,47,53,57}$ one was a retrospective analysis, ${ }^{35}$ and three were surveys. ${ }^{23,42,50}$

\section{Results}

\section{Sample and setting}

Of the original 866 English articles, 38 articles fulfilled our aforementioned criteria and thus were included for analysis in this review. ${ }^{18-55}$ These 38 articles outline the impact of 
anxiety and/or depression on patients living with OA and the challenges these comorbidities present in OA management, wherein some studies also examined approaches on how to address these challenges. The age of patients analyzed in most of these studies was consistent with the age at which $\mathrm{OA}$ and depression are commonly diagnosed. However, one study specified a younger cutoff age range in their inclusion criteria. ${ }^{45}$ Gignac et $\mathrm{al}^{45}$ reported that middle-aged patients with OA (mean age 50.8 years) reported more depression compared to elderly subjects (mean age 67.8 years) having similar OA severity. This difference was attributed to role limitation and dissatisfaction among middle-aged OA individuals. Most studies included both male and female participants. However, in one study, sex was an eligibility criterion, as this study focused solely on female participants. ${ }^{19}$ Studies were carried out in different settings viz university hospital, general practitioner (GP) clinics, and via telephone/ mailed surveys. All studies published after year 2000 were analyzed (Table 1).

\section{Anxiety and depression}

All studies evaluated anxiety and/or depression either as a primary or a secondary objective. Various scoring methods were utilized, of which Centre for Epidemiological Studies Depression Scale (CES-D) ${ }^{58}$ and Hospital Anxiety and Depression Scale (HADS) were most popular. ${ }^{59}$ Both CES-D and HADS have been extensively used and studied, and are considered reliable and valid research tools. ${ }^{60}$ Other scoring methods used were Composite International Diagnostic Interview, ${ }^{13} 36$-Item or the 12-Item Short Form Health Survey (SF-12, SF-36), ${ }^{61}$ Hopkins Symptom Checklist Depression Scale, ${ }^{62}$ Patient Reported Outcome Measurement Information System, ${ }^{63}$ Patient Health Questionnaire (PHQ) ${ }^{64}$ visual analog scale, Arthritis Impact Measurement Scale, ${ }^{65}$ Beck Depression Inventory, ${ }^{66}$ and the Health Education Impact Questionnaire. ${ }^{67}$ Apart from these scores, clinical diagnosis based on patient interviews was also utilized.

\section{OA pathology and disease severity}

Most studies focused on lower extremity OA (hip and knee), with one study examining hand $\mathrm{OA}^{38}$ patients. Diagnosis was based on clinical presentation or radiographs. Patients from the entire spectrum of disease severity were studied. The Kellgren and Lawrence (KL) radiographic grading system was most often used to report OA severity; however, some studies did not use any specific grading method. One study included patients with early (KL I, II) and late (KL III, IV) stage OA. ${ }^{32}$ Pain was a consistent feature across most studies and was assessed primarily using the Western Ontario \&
McMaster Universities Osteoarthritis Index. ${ }^{68}$ In addition to OA, two studies also assessed patients with rheumatoid arthritis. ${ }^{19,33}$

\section{Epidemiology of anxiety and depression in patients with $O A$}

Three studies reported on the prevalence of anxiety and depression in patients with OA. ${ }^{24,29,41}$ Rosemann et al $^{29}$ conducted a cross-sectional survey in 1,021 patients with OA and reported that psychological factors (viz anxiety and depression) were highly prevalent among the patients $(19.76 \%$ of male and $19.16 \%$ of female participants reported a PHQ-9 score of $\geq 15$ ). Similar results were reported by Sale et $\mathrm{al}^{24}$ in a cross-sectional study where $21.3 \%$ of 1,227 participants reported a CES-D score of $\geq 16$. Likewise, Kirkness et $\mathrm{al}^{41}$ reported that major depressive disorder was commonly prevalent in patients scheduled for total knee arthroplasty.

\section{Impact \\ Impact of anxiety and depression on OA symptoms}

Of the 38 studies included in our final analysis, 13 studies examined the impact of anxiety and depression on OA symptoms. ${ }^{18,19,26,31,32,38,43,45,46,48,50,55}$ There was a considerable overlap in reporting impact of these psychological conditions on patients with OA with pain being the key central element. Studies reported that the prevalence of anxiety and depression was interrelated to index joint pain, ${ }^{55}$ pain at multiple sites, ${ }^{31,50}$ pain intensity, ${ }^{25}$ and OA severity. ${ }^{32}$ Pain was in turn associated with depression and its recurrence. ${ }^{46}$ Hawker et $\mathrm{a}^{43}$ also reported that current OA pain predicted future fatigue, disability, and depressed mood. In addition to its impact on OA pain, concurrent depression was also interrelated to significant participation restriction and physical limitation. ${ }^{26,45}$

\section{Impact of anxiety and depression on OA outcomes}

Nine studies examined the impact of anxiety and depression on the outcomes of patients with OA..$^{20,27,30,34,35,37,44,52,53}$ Studies reported that anxiety and depression increased GP visits, ${ }^{52}$ health care utilization, ${ }^{27}$ drug prescriptions, ${ }^{53}$ adversely affected surgical outcomes, ${ }^{30,34,35,37,44}$ and increased postsurgical pain. ${ }^{20}$

\section{Impact of anxiety and depression on patients with OA: sex differences}

Our results indicate that anxiety and depression differentially impact lives of male and female patients with OA. 
Sale et $\mathrm{al}^{24}$ reported that higher level of depressed mood was independently and significantly associated with the female sex.

\section{Management challenges}

Thirteen studies evaluated management challenges in patients with OA with comorbid anxiety and depression. ${ }^{21-23,28,33,36,39,40,42,47,49,51,54}$ The present study found that anxiety and depression posed unique challenges to physicians in 1) diagnosis, 2) structuring a proper management plan, and 3) effective pharmacotherapy.

\section{Challenges in diagnosis of anxiety and depression}

Primary care physicians or GPs infrequently considered or found it difficult to diagnose anxiety and/or depression in patients with OA. ${ }^{28,42}$

\section{Challenges in self-care, collaborative care, social/phone support}

Management regimes advocating self-care, social/phone support, and educational engagements in patients with OA with comorbid anxiety and depression were reported. Lin et $\mathrm{al}^{39}$ reported that systematic depression management (antidepressant pharmacotherapy and/or problem-solving treatment) was more effective than usual care in decreasing pain severity among patients with arthritis with lower initial pain severity, but not among patients with higher initial pain severity. On the contrary, Buszewicz et $\mathrm{al}^{52}$ reported that although self-management reduced anxiety, it had no significant effect on pain, physical functioning, or number of GP visits at 12 months.

\section{Challenges in pharmacotherapy}

Pharmacological challenges exist in managing patients with OA with comorbid anxiety and depression. These challenges juxtaposed with the demographics of this patient cohort (advanced age and presence of other medical comorbidities) make pharmacotherapy difficult. Therefore, it is vital to investigate new treatment modalities that could effectively manage these conditions with minimum adverse effects. The present study found that rofecoxib and tapentadol were reported to improve pain and depressive symptoms of patients with OA. Theiler et $\mathrm{al}^{21}$ assessed the effects of rofecoxib on quality of life (QoL) in elderly patients with painful OA flares who were not responsive to or had adverse reactions to previous NSAID therapy. The authors reported that rofecoxib significantly improved QoL, as measured by the SF-12. Similarly,
Collantes-Esteve and Fernandez-Perez ${ }^{51}$ found rofecoxib to favorably influence patients with OA with self-reported depression. In addition to rofecoxib, use of tapentadol (prolonged and immediate release) has also been reported in patients with chronic painful knee OA. Steigerwald et $\mathrm{al}^{22}$ evaluated effectiveness of tapentadol prolonged release in 195 patients with chronic OA knee pain and found significant improvement in pain intensity, QoL, SF-36, and HADS.

\section{New management approaches: music, video, and yoga}

In recent years, various new and innovative management methodologies have been investigated. Ayral et $\mathrm{al}^{54}$ reported that advocating video education information on the planned procedure before surgery lowered perioperative anxiety. Music therapy and yoga have also been reported to help improve patient anxiety and depression; however, the sample sizes of their respective studies were small. ${ }^{69,70}$

\section{Discussion}

Psychological comorbidities (anxiety and depression) are highly prevalent among patients with OA. ${ }^{24,29,41,49}$ These comorbidities are frequently associated with higher pain and physical limitation, ${ }^{18,19,26,31,32,38,43,45,46,48,50,55}$ poor outcomes to both conservative and surgical interventions, ${ }^{20,30,31,34,35,37,44,47,56}$ and increased pharmacotherapy and health care utilization. ${ }^{23,48}$ Our results indicate that standardized interventions to manage these comorbidities are lacking as a number of different self-care management programs, telephone support programs, video information support programs, and new drug treatments were reported in the literature with varied success. ${ }^{21-23,28,33,36,39,40,42,47,49,51,54}$ This variability in patient care highlights the complex relationship that exists between OA, anxiety, and depression (Table 2). Yet, these comorbidities are commonly overlooked by many primary care physicians and GPs who either solely focus on physical aspects of OA or simply fail to assess patients' psychological state altogether. ${ }^{71}$ It is imperative to recognize these comorbidities, as these can influence disease course and management, ultimately affecting functional outcomes.

Anxiety and depression are interrelated with pain and physical limitation, the two key OA symptoms. Studies in our review have revealed that anxiety and depression can significantly impair QoL of patients by altering pain perception and functional capacity. ${ }^{24}$ Therefore, educating physicians about timely identification of psychosocial factors such as anxiety and depression that may pre-date OA pathology or result as a 
Table 2 Summary of results

\begin{tabular}{|c|c|c|}
\hline Impact & \multicolumn{2}{|l|}{ Summary } \\
\hline Epidemiology & \multicolumn{2}{|c|}{ Psychological factors such as anxiety and depression are commonly prevalent in patients with OA. } \\
\hline OA symptoms & \multicolumn{2}{|c|}{$\begin{array}{l}\text { Anxiety and depression contribute to index joint pain and its intensity. This pain can predict future fatigue, } \\
\text { disability, and depressed mood. }\end{array}$} \\
\hline OA outcomes & \multicolumn{2}{|c|}{$\begin{array}{l}\text { Anxiety and depression increase GP visits, health care and drug utilization, post-surgical pain, and adverse } \\
\text { outcomes. }\end{array}$} \\
\hline Sex differences & \multicolumn{2}{|c|}{$\begin{array}{l}\text { Anxiety and depression differentially impact lives of male and female patients with OA, with females showing } \\
\text { higher levels of depressed mood. }\end{array}$} \\
\hline Management challenges & Summary & Suggestions \\
\hline Challenges in diagnosis & $\begin{array}{l}\text { Physicians found it difficult to diagnose anxiety } \\
\text { and/or depression in patients with OA. }\end{array}$ & $\begin{array}{l}\text { Adopt NICE guidelines toward holistic assessment of } \\
\text { patients with OA. }\end{array}$ \\
\hline $\begin{array}{l}\text { Challenges in self-care, } \\
\text { collaborative care, social/phone } \\
\text { support }\end{array}$ & $\begin{array}{l}\text { Anxiety and depression pose as a challenge to } \\
\text { physicians in structuring a management plan. } \\
\text { Studies have reported use of various } \\
\text { management programs with variable success. }\end{array}$ & $\begin{array}{l}\text { Use "à la carte" approach. Thorough timely patient } \\
\text { assessment required following initiation of program to access } \\
\text { for improvement. }\end{array}$ \\
\hline Challenges in pharmacotherapy & $\begin{array}{l}\text { Rofecoxib and tapentadol were reported to } \\
\text { have favorable results. }\end{array}$ & $\begin{array}{l}\text { Cocktail pharmacotherapy. Other drugs like duloxetine have } \\
\text { been approved by FDA for use in this patient cohort. }\end{array}$ \\
\hline New management approaches & $\begin{array}{l}\text { Music, video, and yoga have been tried with } \\
\text { favorable results. }\end{array}$ & Can be employed as adjuvants. \\
\hline
\end{tabular}

Abbreviations: FDA, US Food and Drug Administration; GP, general practitioner; NICE, National Institute for Health and Care Excellence; OA, osteoarthritis.

consequence of the disease can improve the QoL of patients living with these comorbidities. The National Institute for Health and Care Excellence (NICE) has outlined recommendations regarding holistic assessment of patients with OA (https://www.nice.org.uk/guidance/cg177), which serves as an excellent starting point and it is highly recommended that physicians consult this document. Thus, implementation of appropriate screening questionnaires can help identify these psychological comorbidities at an earlier stage, which could in effect provide adequate lead time to implement a management plan that could improve outcomes and lower future health care burden and costs.

$\mathrm{OA}$ is a progressive disease and a large portion of patients with OA will, at some point, undergo surgery. Patients awaiting surgery can experience anxiety; however, educating them about the procedure and advocating a self-care plan can change health-directed behaviors. While surgery does improve QoL of patients, patients with OA with comorbid anxiety and depression may not experience similar favorable clinical outcomes following joint replacement surgery as seen in patients with OA without these comorbidities, ${ }^{20,30,34,35,37,44,47,56}$ even after a structured rehabilitation program..$^{72}$ Thus, surgical indications in patients with OA with comorbid anxiety and depression should be critically assessed as not all patients report similar benefits following surgery.

As seen in our results, OA management strategies include self-care, collaborative care, social/phone support, pharmacotherapy, music, educational videos about OA procedures, and yoga. Self-care, collaborative care, and social/phone support should be integrated into OA management, as these strategies have been shown to alter comorbid anxiety and depression, as well as resulting physical and emotional pain. Similarly, pharmacotherapy should also be appropriately integrated into OA management; however, this should be done carefully, as the treatment of OA, depression, anxiety, and pain through pharmacotherapy carries the danger of drug interactions and adverse side effects. From our study, we can suggest rofecoxib and tapentadol to improve QoL and pain of patient with OA and encourage the development of new treatment modalities that work in tandem to treat OA symptoms, as well as comorbidities. Additionally, there is evidence that anti-depressant medications such as duloxetine can improve pain in patients with $\mathrm{OA},{ }^{73}$ suggesting a central mechanism that may connect OA pain and depression. Therefore, it would be appropriate to consider implementing anti-depressant/anti-anxiety therapy in tandem with non-steroidal anti-inflammatory drugs and/or analgesic drugs to address these different pain pathways concurrently. This multi-faceted pharmacological approach can greatly benefit patients in this cohort. Other newer modalities such as music, videos, and yoga are management methods that have recently gained more attention, as they have been shown to improve patient outcomes. Music has been shown to reduce levels of anxiety, depression, and pain. Likewise, videos educating patients on their planned surgical procedures have lowered pre-operative anxiety. These modalities can act as adjuvants to current management strategies.

To create individualized OA management strategies, it is essential to recognize that patients with early OA disease experience less anxiety and depression compared to patients with late-stage disease. ${ }^{32}$ Therefore, radiological severity of 
OA can serve as an indicative factor for intensity of depression in patients with OA. This concept should be further investigated. Similarly, sex differences are prevalent independently in OA, anxiety, and depression. ${ }^{74,75}$ Studies have reported that female patients with OA report greater anxiety and depression ${ }^{24,76}$ and lower QoL ${ }^{38}$ than males. Moreover, female patients with OA may have different expectations than their male counterparts and therefore may require a completely different management approach.

It is important to state that present literature fails to fully address the management strategies in dealing with psychological comorbidities seen in patients with OA. It is rather clear that one treatment does not fit all, as seen in the present review. On one end self-management interventions did not improve pain, QoL, or depression, ${ }^{77}$ while on the other hand, self-management did produce improvement in exercise and relaxation activities in depressed patients although not as much as in patients without depression. ${ }^{33}$ These conflicting results highlight the challenges present in the management of these comorbidities today. It should also be highlighted that recruiting and retaining patients in management programs is also challenging and should be further evaluated to increase patient compliance, as depressed patients tend to lack interest from the outset. Furthermore, another factor in need of consideration is age, and how reports of depression/anxiety can differ based on patients' age group. To garner an accurate understanding of how depression/anxiety interacts with OA, it is important to consider the possibility that different age groups experience varying degrees of depression/anxiety, based on a diverse set of factors, such as socioeconomic status and health complications. Recent trends in depression suggest its high prevalence among individuals aged 40-59 years, which may thus affect the presentation of OA to a greater degree in middle-aged cohorts than younger or elderly cohorts. ${ }^{78}$ Therefore, examining the impact and management challenges of anxiety and depression in an age-stratified OA cohort should be further investigated.

Although our results provide a comprehensive summary of the current state of literature, a considerable lack of studies originating from outside of North America and Europe is noted. This could be attributed to the fact that outpatient visits and in-patient admissions for mental health diseases are higher in the US and Europe, ${ }^{79}$ or it could simply underscore a general lack of research initiatives in the developing world, or that psychological conditions largely remain underrecognized and/or under-diagnosed. Thus, the inclusion of studies from developing nations may provide a more detailed picture of the relationship between anxiety, depression, and
OA. We also acknowledge that the exclusion of reports not published in English may have introduced institutional bias. Furthermore, in addition to the inherent weaknesses of the studies reviewed, our study may be skewed by publication bias, as there is a well-described prejudice toward the publication of positive findings. Nevertheless, we believe that the present review accurately presents the current state of evidence concerning the impact and management challenges of anxiety and depression encountered by patients with OA.

\section{Conclusion}

In summary, the majority of evidence regarding impact of anxiety and depression in patients with OA suggests reduced QoL and poor clinical outcomes. The current literature fails to lay a blueprint to tackle the management challenges seen. OA stage-specific stratification may help guide management. However, further studies are needed to formulate definitive management strategies to deal with OA-associated anxiety and depression and should focus on high-quality randomized controlled trials with patients stratified into non-operative, pre-operative/operative, and post-operative groups.

\section{Acknowledgment}

We thank Dr Jason Rockel, Research Associate at Krembil Research Institute, for comments that greatly improved the manuscript.

\section{Disclosure}

The authors report no conflicts of interest in this work

\section{References}

1. Johnson VL, Hunter DJ. The epidemiology of osteoarthritis. Best Pract Res Clin Rheumatol. 2014;28(1):5-15.

2. Lories RJ, Luyten FP. The bone-cartilage unit in osteoarthritis. Nat Rev Rheumatol. 2011;7(1):43-49.

3. Hunter DJ, Schofield D, Callander E. The individual and socioeconomic impact of osteoarthritis. Nat Rev Rheumatol. 2014;10(7):437-441.

4. Litwic A, Edwards MH, Dennison EM, Cooper C. Epidemiology and burden of osteoarthritis. Br Med Bull. 2013;105:185-199.

5. Lawrence RC, Felson DT, Helmick CG, et al; National Arthritis Data Workgroup. Estimates of the prevalence of arthritis and other rheumatic conditions in the United States. Part II. Arthritis Rheum. 2008;58(1):26-35.

6. Axford J, Butt A, Heron C, et al. Prevalence of anxiety and depression in osteoarthritis: use of the Hospital Anxiety and Depression Scale as a screening tool. Clin Rheumatol. 2010;29(11):1277-1283.

7. van Baar ME, Dekker J, Lemmens JA, Oostendorp RA, Bijlsma JW. Pain and disability in patients with osteoarthritis of hip or knee: the relationship with articular, kinesiological, and psychological characteristics. $J$ Rheumatol. 1998;25(1):125-133.

8. Merriam-Webster.com [homepage on the Internet]. "Anxiety"; 2016. Available from: http://www.merriam-webster.com/. Accessed September 16, 2016.

9. American Psychiatric Association. Diagnostic and Statistical Manual of Mental Disorders. Washington, DC: APA; 2013. 
10. Maurer J, Rebbapragada V, Borson S, et al; ACCP Workshop Panel on Anxiety and Depression in COPD. Anxiety and depression in COPD: current understanding, unanswered questions, and research needs. Chest. 2008;134(4 suppl):43S-56S.

11. Januzzi JL Jr, Stern TA, Pasternak RC, DeSanctis RW. The influence of anxiety and depression on outcomes of patients with coronary artery disease. Arch Intern Med. 2000;160(13):1913-1921.

12. Mikocka-Walus AA, Turnbull DA, Moulding NT, Wilson IG, Andrews JM, Holtmann GJ. Controversies surrounding the comorbidity of depression and anxiety in inflammatory bowel disease patients: a literature review. Inflamm Bowel Dis. 2007;13(2):225-234.

13. He Y, Zhang M, Lin EH, et al. Mental disorders among persons with arthritis: results from the World Mental Health Surveys. Psychol Med. 2008;38(11):1639-1650.

14. Neogi T, Nevitt MC, Yang M, Curtis JR, Torner J, Felson DT. Consistency of knee pain: correlates and association with function. Osteoarthritis Cartilage. 2010;18(10):1250-1255.

15. Hansen GR, Streltzer J. The psychology of pain. Emerg Med Clin North Am. 2005;23(2):339-348.

16. Button KS, Ioannidis JP, Mokrysz C, et al. Power failure: why small sample size undermines the reliability of neuroscience. Nat Rev Neurosci. 2013;14(5):365-376.

17. Nuesch E, Trelle S, Reichenbach S, et al. Small study effects in metaanalyses of osteoarthritis trials: meta-epidemiological study. $B M J$. 2010;341:c3515.

18. Zullig LL, Bosworth HB, Jeffreys AS, et al. The association of comorbid conditions with patient-reported outcomes in Veterans with hip and knee osteoarthritis. Clin Rheumatol. 2015;34(8):1435-1441.

19. Yılmaz H, Karaca G, Demir Polat HA, Akkurt HE. Comparison between depression levels of women with knee osteoarthritis, rheumatoid arthritis, and fibromyalgia syndrome: a controlled study. Turk J Phys Med Rehab. 2015;61:197-202.

20. Wylde V, Dixon S, Blom AW. The role of preoperative self-efficacy in predicting outcome after total knee replacement. Musculoskeletal Care. 2012;10(2):110-118.

21. Theiler R, Bischoff HA, Good M, Uebelhart D. Rofecoxib improves quality of life in patients with hip or knee osteoarthritis. Swiss Med Wkly. 2002;132(39-40):566-573.

22. Steigerwald I, Muller M, Kujawa J, Balblanc JC, Calvo-Alen J. Effectiveness and safety of tapentadol prolonged release with tapentadol immediate release on-demand for the management of severe, chronic osteoarthritis-related knee pain: results of an open-label, phase $3 \mathrm{~b}$ study. J Pain Res. 2012;5:121-138.

23. Stamm TA, Pieber K, Blasche G, Dorner TE. Health care utilisation in subjects with osteoarthritis, chronic back pain and osteoporosis aged 65 years and more: mediating effects of limitations in activities of daily living, pain intensity and mental diseases. Wien Med Wochenschr. 2014;164(7-8):160-166.

24. Sale JE, Gignac M, Hawker G. The relationship between disease symptoms, life events, coping and treatment, and depression among older adults with osteoarthritis. $J$ Rheumatol. 2008;35(2):335-342.

25. Rosemann T, Laux G, Szecsenyi J, Wensing M, Grol R. Pain and osteoarthritis in primary care: factors associated with pain perception in a sample of 1,021 patients. Pain Med. 2008;9(7):903-910.

26. Rosemann T, Laux G, Kuehlein T. Osteoarthritis and functional disability: results of a cross sectional study among primary care patients in Germany. BMC Musculoskelet Disord. 2007;8:79.

27. Rosemann T, Joos S, Szecsenyi J, Laux G, Wensing M. Health service utilization patterns of primary care patients with osteoarthritis. BMC Health Serv Res. 2007;7:169.

28. Rosemann T, Gensichen J, Sauer N, Laux G, Szecsenyi J. The impact of concomitant depression on quality of life and health service utilisation in patients with osteoarthritis. Rheumatol Int. 2007;27(9):859-863.

29. Rosemann T, Backenstrass M, Joest K, Rosemann A, Szecsenyi J, Laux G. Predictors of depression in a sample of 1,021 primary care patients with osteoarthritis. Arthritis Rheum. 2007;57(3):415-422.
30. Pinto PR, McIntyre T, Ferrero R, Almeida A, Araujo-Soares V. Predictors of acute postsurgical pain and anxiety following primary total hip and knee arthroplasty. J Pain. 2013;14(5):502-515.

31. Perruccio AV, Power JD, Evans HM, et al. Multiple joint involvement in total knee replacement for osteoarthritis: effects on patient-reported outcomes. Arthritis Care Res (Hoboken). 2012;64(6):838-846.

32. Ozcakir S, Raif SL, Sivrioglu K, Kucukcakir N. Relationship between radiological severity and clinical and psychological factors in knee osteoarthritis. Clin Rheumatol. 2011;30(12):1521-1526.

33. Nour K, Laforest S, Gauvin L, Gignac M. Behavior change following a self-management intervention for housebound older adults with arthritis: an experimental study. Int J Behav Nutr Phys Act. 2006;3:12.

34. Montin L, Leino-Kilpi H, Katajisto J, Lepisto J, Kettunen J, Suominen T. Anxiety and health-related quality of life of patients undergoing total hip arthroplasty for osteoarthritis. Chronic Illn. 2007;3(3):219-227.

35. Marks R. Comorbid depression and anxiety impact hip osteoarthritis disability. Disabil Health J. 2009;2(1):27-35.

36. Marks R. Physical and psychological correlates of disability among a cohort of individuals with knee osteoarthritis. Can J Aging. 2007;26(4):367-377.

37. Lopez-Olivo MA, Landon GC, Siff SJ, et al. Psychosocial determinants of outcomes in knee replacement. Ann Rheum Dis. 2011;70(10):1775-1781.

38. Liu R, Damman W, Beaart-van de Voorde L, et al. Aesthetic dissatisfaction in patients with hand osteoarthritis and its impact on daily life. Scand J Rheumatol. 2016;45(3):219-223.

39. Lin EH, Tang L, Katon W, Hegel MT, Sullivan MD, Unutzer J. Arthritis pain and disability: response to collaborative depression care. Gen Hosp Psychiatry. 2006;28(6):482-486.

40. Lin EH, Katon W, Von Korff M, et al; IMPACT Investigators. Effect of improving depression care on pain and functional outcomes among older adults with arthritis: a randomized controlled trial. JAMA. 2003;290(18):2428-2429.

41. Kirkness CS, McAdam-Marx C, Unni S, et al. Characterization of patients undergoing total knee arthroplasty in a real-world setting and pain-related medication prescriptions for management of postoperative pain. J Pain Palliat Care Pharmacother. 2012;26(4):326-333.

42. Kingsbury SR, Conaghan PG. Current osteoarthritis treatment, prescribing influences and barriers to implementation in primary care. Prim Health Care Res Dev. 2012;13(4):373-381.

43. Hawker GA, Gignac MA, Badley E, et al. A longitudinal study to explain the pain-depression link in older adults with osteoarthritis. Arthritis Care Res (Hoboken). 2011;63(10):1382-1390.

44. Hanusch BC, O'Connor DB, Ions P, Scott A, Gregg PJ. Effects of psychological distress and perceptions of illness on recovery from total knee replacement. Bone Joint J. 2014;96-B(2):210-216.

45. Gignac MA, Backman CL, Davis AM, Lacaille D, Cao X, Badley EM. Social role participation and the life course in healthy adults and individuals with osteoarthritis: are we overlooking the impact on the middle-aged? Soc Sci Med. 2013;81:87-93.

46. Gerrits MM, van Oppen P, Leone SS, van Marwijk HW, van der Horst HE, Penninx BW. Pain, not chronic disease, is associated with the recurrence of depressive and anxiety disorders. BMC Psychiatry. 2014; $14: 187$.

47. Ellis HB, Howard KJ, Khaleel MA, Bucholz R. Effect of psychopathology on patient-perceived outcomes of total knee arthroplasty within an indigent population. J Bone Joint Surg Am. 2012;94(12):e84.

48. Dieppe P, Cushnaghan J, Tucker M, Browning S, Shepstone L. The Bristol 'OA500 study': progression and impact of the disease after 8 years. Osteoarthritis Cartilage. 2000;8(2):63-68.

49. Dailiana ZH, Papakostidou I, Varitimidis S, et al. Patient-reported quality of life after primary major joint arthroplasty: a prospective comparison of hip and knee arthroplasty. BMC Musculoskelet Disord. 2015; $16: 366$.

50. Croft P, Jordan K, Jinks C. "Pain elsewhere" and the impact of knee pain in older people. Arthritis Rheum. 2005;52(8):2350-2354. 
51. Collantes-Estevez E, Fernandez-Perez C. Improved control of osteoarthritis pain and self-reported health status in non-responders to celecoxib switched to rofecoxib: results of PAVIA, an open-label post-marketing survey in Spain. Curr Med Res Opin. 2003;19(5):402-410.

52. Buszewicz M, Rait G, Griffin M, et al. Self management of arthritis in primary care: randomised controlled trial. BMJ. 2006;333(7574):879

53. Blagestad T, Nordhus IH, Gronli J, et al. Prescription trajectories and effect of total hip arthroplasty on the use of analgesics, hypnotics, antidepressants, and anxiolytics: results from a population of total hip arthroplasty patients. Pain. 2016;157(3):643-651.

54. Ayral X, Gicquere C, Duhalde A, Boucheny D, Dougados M. Effects of video information on preoperative anxiety level and tolerability of joint lavage in knee osteoarthritis. Arthritis Rheum. 2002;47(4):380-382.

55. Axford J, Heron C, Ross F, Victor CR. Management of knee osteoarthritis in primary care: pain and depression are the major obstacles. $J$ Psychosom Res. 2008;64(5):461-467.

56. Riddle DL, Kong X, Fitzgerald GK. Psychological health impact on 2-year changes in pain and function in persons with knee pain: data from the Osteoarthritis Initiative. Osteoarthritis Cartilage. 2011;19(9):1095-1101.

57. Kim KW, Han JW, Cho HJ, et al. Association between comorbid depression and osteoarthritis symptom severity in patients with knee osteoarthritis. J Bone Joint Surg Am . 2011;93(6):556-563.

58. Radloff LS. The CES-D Scale: a self-report depression scale for research in the general population. Appl Psychol Measurement. 1977;1:385-401.

59. Zigmond AS, Snaith RP. The hospital anxiety and depression scale. Acta Psychiatr Scand. 1983;67(6):361-370.

60. Bjelland I, Dahl AA, Haug TT, Neckelmann D. The validity of the Hospital Anxiety and Depression Scale. An updated literature review. J Psychosom Res. 2002;52(2):69-77.

61. Ware J Jr, Kosinski M, Keller SD. A 12-Item Short-Form Health Survey: construction of scales and preliminary tests of reliability and validity. Med Care. 1996;34(3):220-233.

62. Derogatis LR, Lipman RS, Rickels K, Uhlenhuth EH, Covi L. The Hopkins Symptom Checklist (HSCL). A measure of primary symptom dimensions. Mod Probl Pharmacopsychiatry. 1974;7(0):79-110.

63. Cella D, Riley W, Stone A, et al; PROMIS Cooperative Group. The patient-reported outcomes measurement information system (PROMIS) developed and tested its first wave of adult selfreported health outcome item banks: 2005-2008. J Clin Epidemiol. 2010;63(11):1179-1194.

64. Spitzer RL, Kroenke K, Williams JB. Validation and utility of a selfreport version of PRIME-MD: the PHQ primary care study. Primary care evaluation of mental disorders. Patient Health Questionnaire. JAMA. 1999;282(18):1737-1744.
65. Meenan RF, Gertman PM, Mason JH. Measuring health status in arthritis. The arthritis impact measurement scales. Arthritis Rheum. 1980;23(2):146-152.

66. Beck AT, Ward CH, Mendelson M, Mock J, Erbaugh J. An inventory for measuring depression. Arch Gen Psychiatry. 1961;4:561-571.

67. Osborne RH, Elsworth GR, Whitfield K. The Health Education Impact Questionnaire (heiQ): an outcomes and evaluation measure for patient education and self-management interventions for people with chronic conditions. Patient Educ Couns. 2007;66(2):192-201.

68. Bellamy N. The WOMAC knee and hip osteoarthritis indices: development, validation, globalization and influence on the development of the AUSCAN Hand Osteoarthritis Indices. Clin Exp Rheumatol. 2005;23(5 suppl 39):S148-S153.

69. Middleton KR, Ward MM, Haaz S, et al. A pilot study of yoga as selfcare for arthritis in minority communities. Health Qual Life Outcomes. 2013;11:55

70. Ottaviani S, Bernard JL, Bardin T, Richette P. Effect of music on anxiety and pain during joint lavage for knee osteoarthritis. Clin Rheumatol. 2012;31(3):531-534.

71. Turner J, Kelly B. Emotional dimensions of chronic disease. West $J$ Med. 2000;172(2):124-128.

72. von der Hoeh NH, Voelker A, Gulow J, Uhle U, Przkora R, Heyde CE. Impact of a multidisciplinary pain program for the management of chronic low back pain in patients undergoing spine surgery and primary total hip replacement: a retrospective cohort study. Patient Saf Surg. 2014;8:34

73. Abou-Raya S, Abou-Raya A, Helmii M. Duloxetine for the management of pain in older adults with knee osteoarthritis: randomised placebocontrolled trial. Age Ageing. 2012;41(5):646-652.

74. McLean CP, Asnaani A, Litz BT, Hofmann SG. Gender differences in anxiety disorders: prevalence, course of illness, comorbidity and burden of illness. J Psychiatr Res. 2011;45(8):1027-1035.

75. O'Connor MI. Sex differences in osteoarthritis of the hip and knee. $J$ Am Acad Orthop Surg. 2007;15(suppl 1):S22-S25.

76. Theis KA, Helmick CG, Hootman JM. Arthritis burden and impact are greater among U.S. women than men: intervention opportunities. $J$ Womens Health (Larchmt). 2007;16(4):441-453.

77. Crotty M, Prendergast J, Battersby MW, et al. Self-management and peer support among people with arthritis on a hospital joint replacement waiting list: a randomised controlled trial. Osteoarthritis Cartilage. 2009;17(11):1428-1433.

78. Pratt LA, Brody DJ. Depression in the U.S. Household Population, 2009-2012. Hyattsville, MD: National Center for Health Statistics; 2014.

79. WHO. Mental Health Atlas 2014. Geneva: WHO; 2015.
Open Access Rheumatology: Research and Reviews

\section{Publish your work in this journal}

Open Access Rheumatology: Research and Reviews is an international, peerreviewed, open access journal publishing original research, reports, editorials, reviews and commentaries on all aspects of clinical and experimental rheumatology in the clinic and laboratory including the following topics: Pathology, pathophysiology of rheumatological diseases; Investigation, treatment and management of rheumatological diseases; Clinical trials and novel pharmacologi$\mathrm{cal}$ approaches for the treatment of rheumatological disorders. The manuscript management system is completely online and includes a very quick and fair peer-review system, which is all easy to use. Visit http://www.dovepress.com/ testimonials.php to read real quotes from published authors. 